\title{
Article \\ Compact Full Ka-Band Waveguide Directional Coupler Based on Rectangular Aperture Array with Stairs
}

\author{
Xida Deng ${ }^{1}\left(\mathbb{D}\right.$, Ge Dong ${ }^{1, *}$, Xuan Dai ${ }^{2}{ }^{(1)}$ and Jinxiang Deng ${ }^{3}$ \\ 1 School of Aerospace Engineering, Tsinghua University, Beijing 100084, China; dxd20@mails.tsinghua.edu.cn \\ 2 School of Information and Electronics, Beijing Institute of Technology, Beijing 100081, China; \\ 2702002011@bit.edu.cn \\ 3 School of Physics and Optoelectronics, Faculty of Science, Beijing University of Technology, \\ Beijing 100124, China; jdeng@bjut.edu.cn \\ * Correspondence: dongge@tsinghua.edu.cn
}

Citation: Deng, X.; Dong, G.; Dai, X.; Deng, J. Compact Full Ka-Band Waveguide Directional Coupler Based on Rectangular Aperture Array with Stairs. Micromachines 2021, 12, 745. https://doi.org/10.3390/mi12070745

Academic Editor: Piotr Kurgan

Received: 4 June 2021

Accepted: 23 June 2021

Published: 25 June 2021

Publisher's Note: MDPI stays neutral with regard to jurisdictional claims in published maps and institutional affiliations.

Copyright: (c) 2021 by the authors. Licensee MDPI, Basel, Switzerland. This article is an open access article distributed under the terms and conditions of the Creative Commons Attribution (CC BY) license (https:// creativecommons.org/licenses/by/ $4.0 /)$.

\begin{abstract}
This article presents a compact $3 \mathrm{~dB}$ waveguide directional coupler with full waveguide bandwidth. It consists of a pair of rectangular waveguides with stairs structures in the coupling region. The waveguides are placed parallel to each other along their broad wall, which has a rectangular aperture array. The compact size, broad bandwidth, good in-band coupling flatness, and good return loss are achieved by using the proposed structure. For verification purposes, a prototype of the proposed coupler was designed, manufactured, and measured. The experimental results show that over the full waveguide bandwidth a return loss of input port better than $17.46 \mathrm{~dB}$, coupling strength varying between $-2.74 \mathrm{~dB}$ and $-3.80 \mathrm{~dB}$, power-split unbalance within $0.76 \mathrm{~dB}$, and an isolation better than $20.82 \mathrm{~dB}$ were obtained. The length of the coupling region was only $15.82 \mathrm{~mm}$.
\end{abstract}

Keywords: compact directional coupler; microwave coupler; full bandwidth; $3 \mathrm{~dB}$; rectangular aperture

\section{Introduction}

Directional couplers are widely used in modern microwave and millimeter-wave applications such as radar systems, communication systems, and microwave imaging systems, which require power combining, power dividing, or power sampling. Waveguide structures are often used in high-frequency systems or high-power systems, because of their low insert losses and high-power handling characteristics.

As early as 1944, an example of waveguide directional coupler named the Bethe-hole coupler [1] was proposed. It has a single round hole on the common broad wall between a pair of rectangular waveguides. However, it is difficult to achieve broad bandwidth, tight coupling strength, and good coupling flatness. Some scholars proposed many new structures to improve the Bethe-hole coupler. The authors in [2] exhibit a cavity-type directional coupler using a simple structure that is easy to manufacture. In Reference [3], the Riblet coupler is presented, which consists of a short-slot hybrid junction. A simple compact narrow-wall directional coupler is developed in [4]. Multi-apertures are used in directional couplers in [5]. Moreover, multiport waveguide directional couplers are designed in [6].

In recent years, to satisfy the requirements of modern systems, many approaches have been presented to enhance coupling strength and enlarge bandwidth, including three coupling branch couplers [7], multilayer couplers [8], branch-line couplers [9], highorder directional couplers [10], and three-dimensional couplers [11]. These structures obviously expand the operation bandwidth. In Reference [12], a directional coupler using a printed ridge gap waveguide is proposed. Some new structures using substrate-integrated waveguide (SIW) are designed in [13-17]. Large apertures with transition structures [18] are presented to reduce the coupler size. They usually take several operating wavelengths 
to widen the bandwidth. It is difficult to achieve broad bandwidth or tight coupling strength with compact size.

The Ka band is a commonly used band for satellite communications, radar detection, and microwave imaging. In this article, we explain how coupling strength within $-3.27 \pm 0.53 \mathrm{~dB}$ over a full Ka band can be achieved simultaneously in compact size by using the novel rectangular aperture array with stairs, which are shown in Figure 1. The large rectangular aperture array (shown in Figure 1a) with floors (shown in Figure 1b,c) is first used in E-plane coupler. The 3D-structure diagram of the proposed coupler is shown in Figure 1d. This new structure can not only enhance the coupling strength effectively, but also reduce the size of the coupler. The floors (shown Figure 1b) can enhance the coupling strength and match the standard rectangular waveguide. Thus, this design can further decrease the size of the coupler. This structure can make the coupler size smaller than the coupler presented in [18]. The length of the coupling region (shown in Figure 1c) is only $15.82 \mathrm{~mm}$, which is only $1.35 \times \lambda \mathrm{g}$ ( $\lambda \mathrm{g}$ is operation wavelength of center frequency). A sample coupler was manufactured and measured and is described herein. The coupling coefficient is $-3.27 \pm 0.53 \mathrm{~dB}$ in the operation bandwidth varying from $26.5 \mathrm{GHz}$ to $40 \mathrm{GHz}$, in which the return loss is better than $17.46 \mathrm{~dB}$, and the isolation is higher than $20.82 \mathrm{~dB}$. To the authors' knowledge, no such compact $3 \mathrm{~dB}$ waveguide directional coupler with full waveguide bandwidth and good coupling coefficient has ever been presented before. The proposed coupler and some recently reported $3 \mathrm{~dB}$ directional couplers [11,18-21] are compared in Table 1.

Table 1. Performance comparison of some recently reported $3 \mathrm{~dB}$ directional couplers.

\begin{tabular}{|c|c|c|c|c|c|}
\hline Coupler & Frequency $(\mathrm{GHz})$ & $\begin{array}{l}\text { Coupling Strength } \\
\text { Imbalance (dB) }\end{array}$ & Bandwidth (\%) & Relative Length & Type \\
\hline [11] & $31-36.7$ & \pm 0.54 & 16.8 & $1.41 \times \lambda \mathrm{g}$ & SIW \\
\hline [18] & $6.57-9.99$ & \pm 0.6 & 41.3 & $3.37 \times \lambda g$ & RW \\
\hline [19] & $10.675-13.325$ & \pm 0.5 & 22.08 & $1.66 \times \lambda \mathrm{g}$ & HMSIW \\
\hline [20] & $13-17$ & \pm 0.5 & 26.67 & $1.41 \times \lambda \mathrm{g}$ & ESIW \\
\hline$[21]$ & $33-37$ & \pm 0.33 & 11.43 & $0.71 \times \lambda \mathrm{g}$ & SIW \\
\hline This work & $26.5-40$ & \pm 0.53 & 40.6 & $1.35 \times \lambda g$ & RW \\
\hline
\end{tabular}

HMSIW: half-mode substrate-integrated waveguide. RW: rectangular waveguide. ESIW: empty substrate-integrated waveguide. SIW: substrate-integrated waveguide. $\lambda \mathrm{g}$ : operation wavelength of the center frequency. 


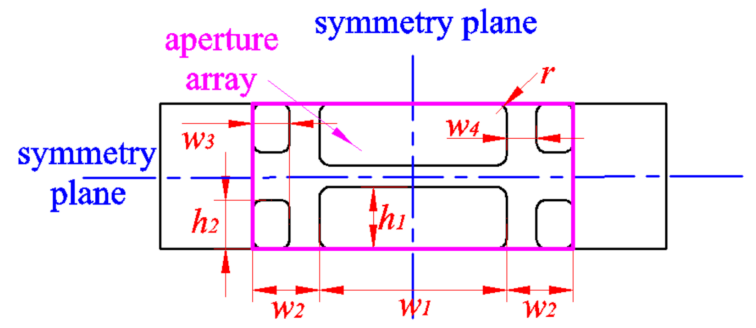

(a)

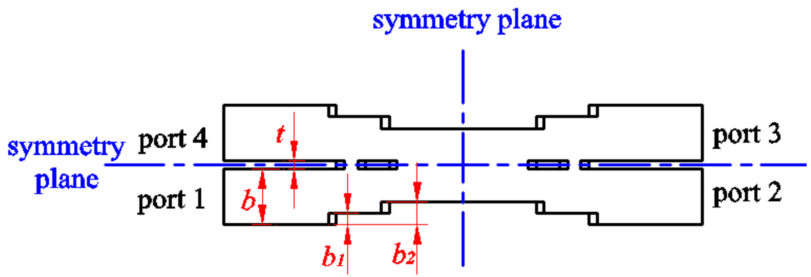

(b)

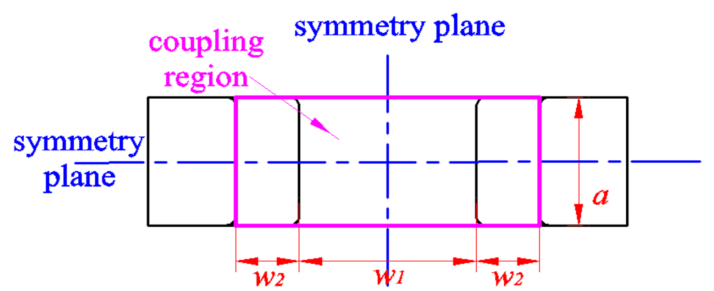

(c)

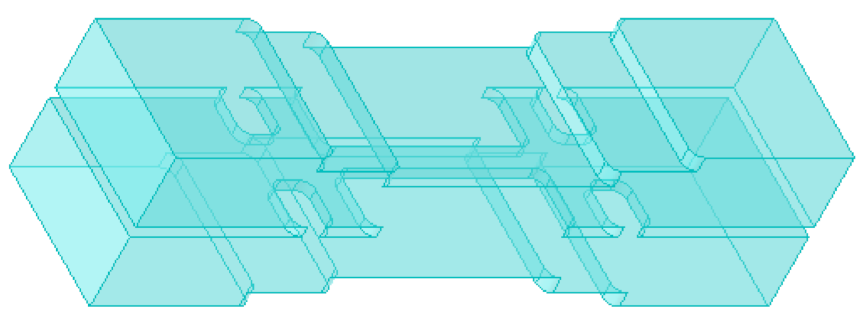

(d)

Figure 1. The proposed coupler: (a) rectangular aperture array, (b) side view, (c) top view, and (d) 3D-structure diagram.

\section{Coupler Configuration}

The configuration and port nominations of the proposed coupler, which includes three pairs of rectangular aperture arrays and the stairs structures placed in the coupling region of two rectangular waveguides, are shown in Figure 1. The main waveguide as well as the branch one are placed in parallel, and they are coupled to each other by three pairs of large aperture arrays in their common broad wall. Stairs structures are placed in the coupling region to enhance the coupling strength and to match the dimensions of standard rectangular waveguides $(\mathrm{a}=7.12 \mathrm{~mm}, \mathrm{~b}=3.56 \mathrm{~mm})$.

The design results from the different numbers of rectangular apertures are listed in Table 2, with the bandwidth all assumed to be the same as the full WR-28 waveguide bandwidth, which is from $26.5 \mathrm{GHz}$ to $40 \mathrm{GHz}$. The performance of the presented coupler is improved as the number of apertures and stairs increases. However, as the number of apertures increases, the length of the coupling region becomes longer. As a compromise, three pairs of rectangular aperture arrays are used in our prototype coupler.

$\mathrm{TE}_{10}$ mode is used in the proposed coupler. The coupling is less frequency dependent. The simulated surface current density is shown at $33 \mathrm{GHz}$ in Figure 2. It can be observed that the signal, fed at port 1 , is properly coupled at port 3 , and port 4 is isolated. The surface current can flow into another waveguide across the large aperture array (Figure 1a), 
which is placed at the edge of the rectangular waveguide broadside. Further, the proposed structure reduces the size more significantly than the conventional designs.

Table 2. Performance of $3 \mathrm{~dB}$ directional coupler with different number of large apertures.

\begin{tabular}{|c|c|c|c|c|}
\hline Number of Apertures & Coupling Imbalance (dB) & Through Flatness (dB) & Return Loss (dB) & Coupler Model \\
\hline $2 \times 1$ & $3.17 \pm 0.92$ & $3.4 \pm 1.2$ & 15.19 & \\
\hline $2 \times 2$ & $3.11 \pm 0.7$ & $3.23 \pm 0.89$ & 17.65 & \\
\hline $2 \times 3$ & $3.14 \pm 0.46$ & $3.13 \pm 0.48$ & 18.68 & \\
\hline
\end{tabular}

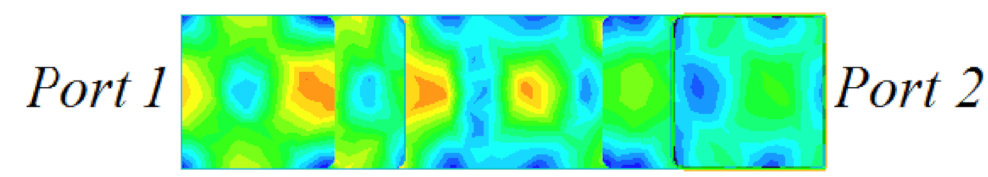

(a)

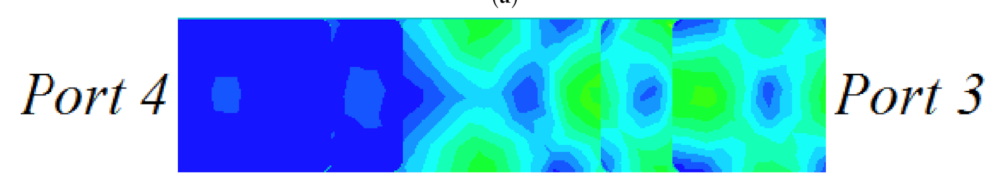

(b)

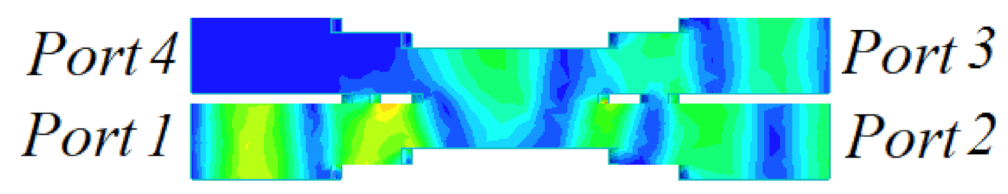

(c)

Figure 2. Surface current density at $33 \mathrm{GHz}$ : (a) bottom view, (b) top view, and (c) side view.

Figure $3 a-f$ illustrates the simulated $S_{21}$ and $S_{31}$ magnitudes of the proposed coupler with one parameter varied, where the other dimensions are fixed. Figure $3 a, b$ shows the relationship between the heights of the aperture array and $S_{21}, S_{31}$ magnitudes. As $h_{1}, h_{2}$ become bigger, the $S_{21}$ magnitude becomes smaller and the $S_{31}$ magnitude becomes bigger. The higher frequency $S$ parameter changes faster than the lower frequency $S$ parameter. As is shown in Figure $3 c, d$, as $w_{1}$ and $w_{3}$ become bigger, the $S_{21}$ magnitude becomes smaller and the $S_{31}$ magnitude becomes bigger. The lower frequency is more sensitive to the width of coupling holes. In Figure $3 e$, we can see that the $S_{31}$ magnitude is sensitive to $b_{1}$ around $35 \mathrm{GHz}$. The higher frequency is more sensitive to $b_{2}$ than the lower frequency, which is depicted in Figure 3f. It is found that there are two ways to change the coupling coefficient: one is to adjust the height of stairs $\left(b_{1}, b_{2}\right)$ and the thickness of the common wall $(t)$, while the other way is to change the parameters of the rectangular apertures $\left(\mathrm{w}_{1}, \mathrm{~h}_{1}, \mathrm{w}_{3}\right.$, and $\left.\mathrm{h}_{2}\right)$. The isolation of the coupler is influenced by the dimension of $\mathrm{w}_{4}$. 


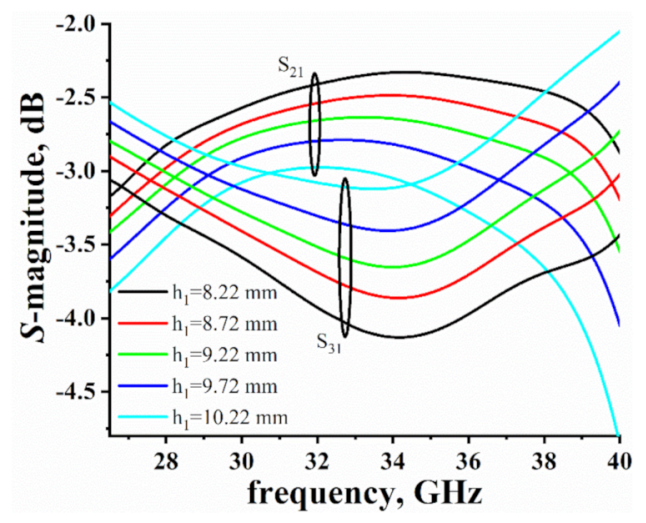

(a)

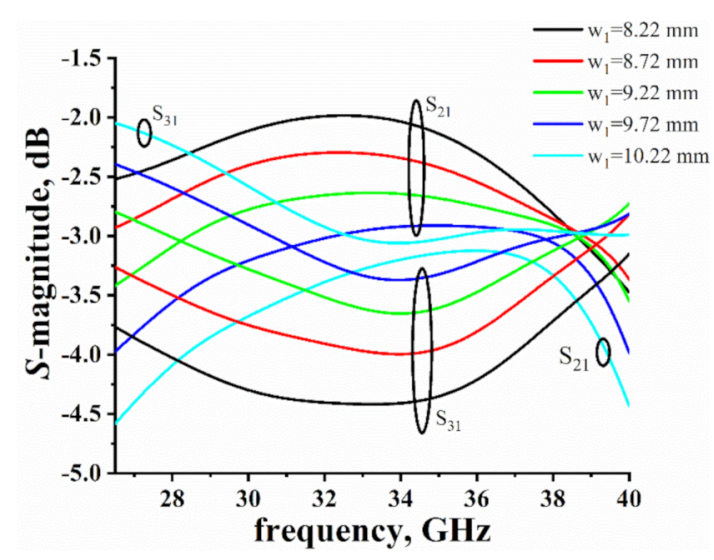

(c)

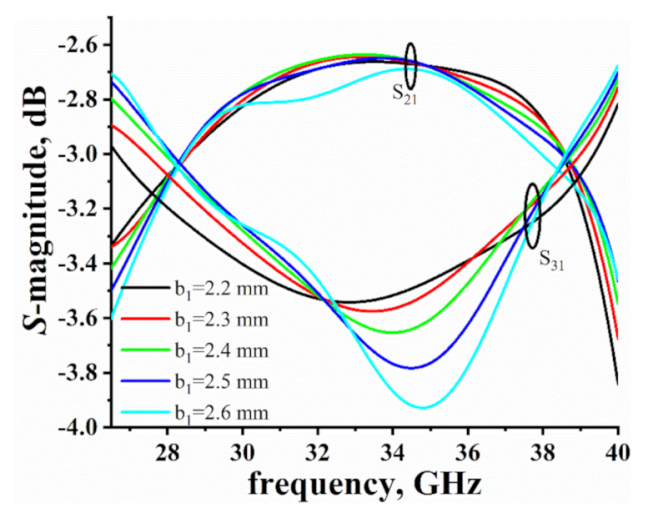

(e)

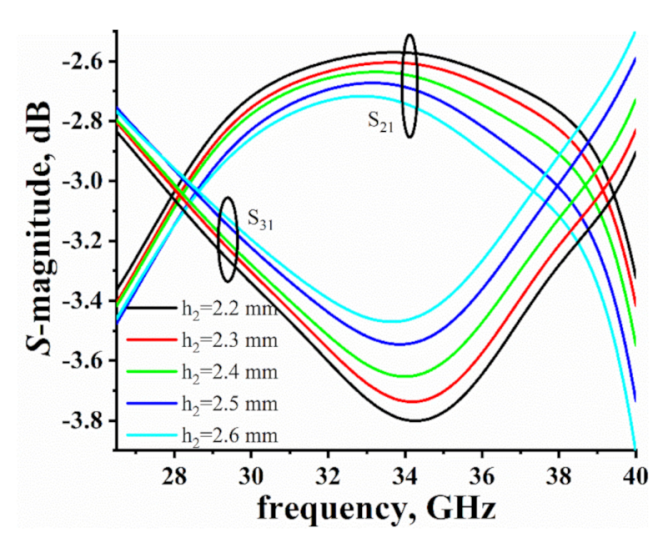

(b)

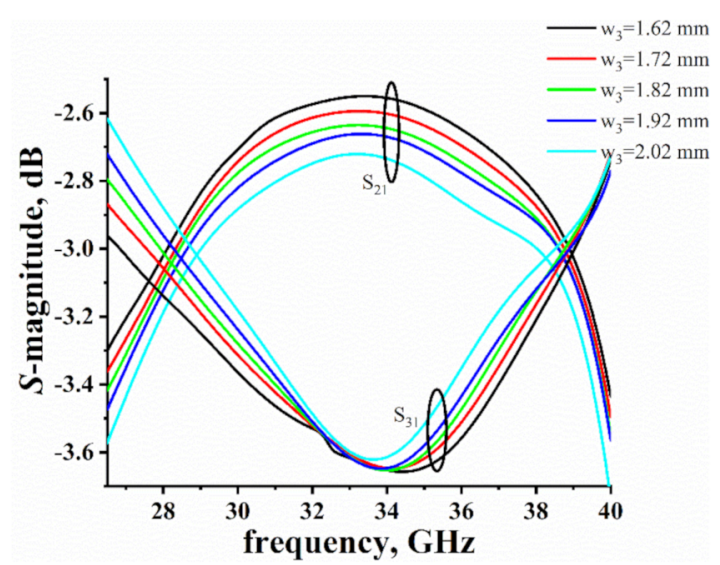

(d)

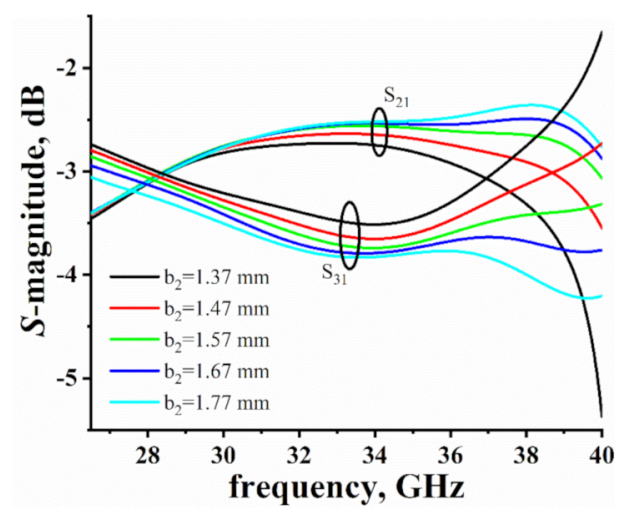

(f)

Figure 3. Simulated $S_{21}$ and $S_{31}$ magnitudes of the proposed coupler with: (a) varied $h_{1}$ where the other dimensions are fixed as $\mathrm{a}=7.12, \mathrm{~b}=3.556, \mathrm{r}=0.5, \mathrm{t}=0.5, \mathrm{~b}_{1}=0.71, \mathrm{~b}_{2}=1.47, \mathrm{w}_{1}=9.22, \mathrm{w}_{3}=1.82, \mathrm{~h}_{2}=2.4$, and $\mathrm{w}_{2}=3.3 ;(\mathrm{b}) \mathrm{varied}_{2}$ where the other dimensions are fixed as $\mathrm{a}=7.12, \mathrm{~b}=3.556, \mathrm{r}=0.5, \mathrm{t}=0.5, \mathrm{~b}_{1}=0.71, \mathrm{~b}_{2}=1.47, \mathrm{w}_{1}=9.22, \mathrm{~h}_{1}=3.03, \mathrm{w}_{3}=1.82$, and $\mathrm{w}_{2}=3.3$; $(\mathbf{c})$ varied $\mathrm{w}_{1}$ where the other dimensions are fixed as $\mathrm{a}=7.12, \mathrm{~b}=3.556, \mathrm{r}=0.5, \mathrm{t}=0.5, \mathrm{~b}_{1}=0.71, \mathrm{~b}_{2}=1.47$, $\mathrm{h}_{1}=3.03, \mathrm{w}_{3}=1.82, \mathrm{~h}_{2}=2.4$, and $\mathrm{w}_{2}=3.3 ;(\mathrm{d})$ varied $\mathrm{w}_{3}$ where the other dimensions are fixed as $\mathrm{a}=7.12, \mathrm{~b}=3.556, \mathrm{r}=0.5$, $\mathrm{t}=0.5, \mathrm{~b}_{1}=0.71, \mathrm{~b}_{2}=1.47, \mathrm{w}_{1}=9.22, \mathrm{~h}_{1}=3.03, \mathrm{~h}_{2}=2.4$, and $\mathrm{w}_{2}=3.3 ;(\mathrm{e})$ varied $\mathrm{b}_{1}$ where the other dimensions are fixed as $\mathrm{a}=7.12, \mathrm{~b}=3.556, \mathrm{r}=0.5, \mathrm{t}=0.5, \mathrm{~b}_{2}=1.47, \mathrm{w}_{1}=9.22, \mathrm{~h}_{1}=3.03, \mathrm{w}_{3}=1.82, \mathrm{~h}_{2}=2.4$, and $\mathrm{w}_{2}=3.3$; (f) varied $\mathrm{b}_{2}$ where the other dimensions are fixed as $\mathrm{a}=7.12, \mathrm{~b}=3.556, \mathrm{r}=0.5, \mathrm{t}=0.5, \mathrm{~b}_{1}=0.71, \mathrm{w}_{1}=9.22, \mathrm{~h}_{1}=3.03, \mathrm{w}_{3}=1.82, \mathrm{~h}_{2}=2.4$, and $\mathrm{w}_{2}=3.3$ (all in millimeters).

\section{Coupler Design and Simulation Results}

To show the design process of the compact coupler, a $3 \mathrm{~dB}$ coupler in full Ka band with novel rectangular aperture arrays and stairs was designed. The well-known commercial 
simulator HFSS (Ansys, Pittsburgh, Pennsylvania, U.S.) was used to simulate the coupler. Before the design process, we assumed that the structures of the two waveguides are the same as each other and placed parallel. The structure of the sample coupler is symmetric with the middle planes, which is shown in Figure 1. A perfect conductor was used to build the model and a discrete sweep type was used in the simulation. The process is described as follows. First, choose a standard rectangular waveguide (WR-28) (Guangsheng metal products company, Cangzhou City, Hebei Province, China) to meet the required operating frequency. Second, tune $t, b_{1}, b_{2}, w_{1}, h_{1}, w_{3}$, and $h_{2}$ (the size of rectangular holes and the height of floors) to make the coupling strength close to $3 \mathrm{~dB}$. The coupling strength is determined by the size of rectangular coupling holes and the size of the height of floors simultaneously. If the rectangular holes become smaller, the height of floors must change to a bigger size. On the other side, if the rectangular holes become bigger, the height of floors must change to a smaller size. A compromise must be made between the size of rectangular holes and the height of floors. Then, adjust $\mathrm{w}_{2}$ to make the $\mathrm{S}_{11}$ magnitude better. Finally, a genetic algorithm is used to optimize $t, b_{1}, b_{2}, w_{1}, h_{1}, w_{3}, h_{2}$, and $w_{2}$, and to make the $S_{21}$ magnitude and $S_{31}$ magnitude balance in the operating frequency. The dimensions of the variables depicted in Figure 1 were chosen as follows: $a=7.12, b=3.556$, $\mathrm{r}=0.5, \mathrm{t}=0.5, \mathrm{~b}_{1}=0.71, \mathrm{~b}_{2}=1.47, \mathrm{w}_{1}=9.22, \mathrm{~h}_{1}=3.03, \mathrm{w}_{3}=1.82, \mathrm{~h}_{2}=2.4$, and $\mathrm{w}_{2}=3.3($ all in millimeter). The simulation curves are shown in Figure $4 a$, in which the $S_{11}$ magnitude and $S_{41}$ magnitude were below $-18.68 \mathrm{~dB}$ and $-19.15 \mathrm{~dB}$, respectively, over full waveguide bandwidth. The $S_{21}$ magnitude and $S_{31}$ magnitude varied between $-3.62 \mathrm{~dB}$ and $-2.65 \mathrm{~dB}$ from $26.5 \mathrm{GHz}$ to $40 \mathrm{GHz}$.

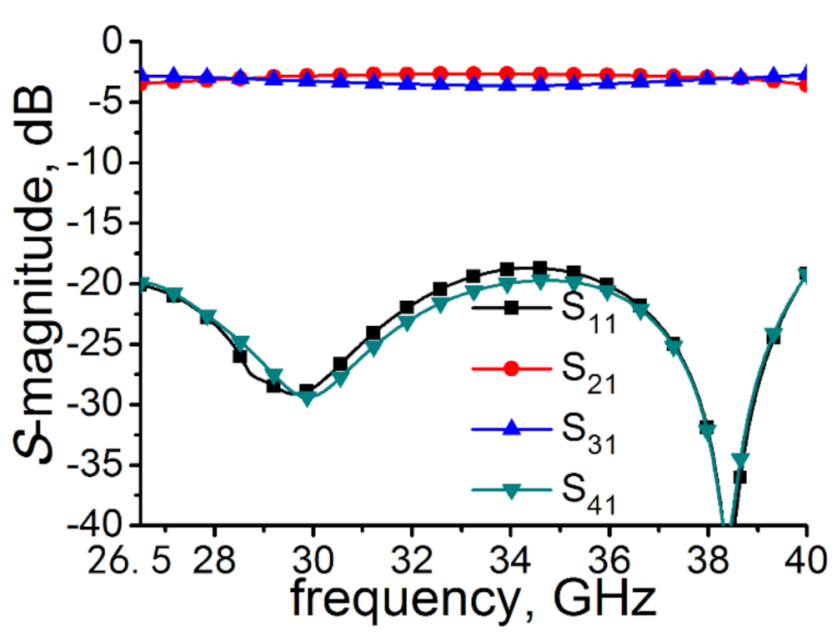

(a)

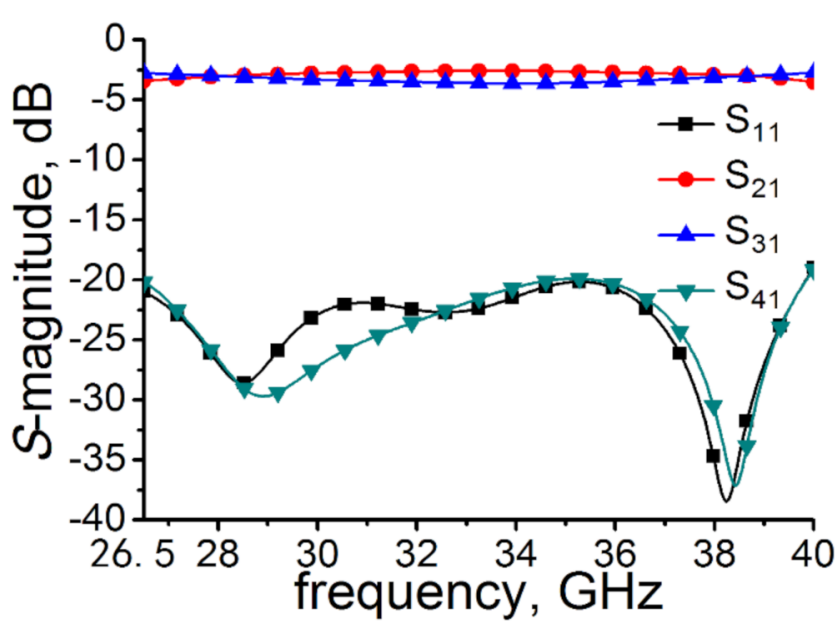

(b)

Figure 4. Simulated results of sample coupler (a) without transitions and (b) with transitions.

For measurement purposes, two $90^{\circ}$ transitions were added to the structure in order to facilitate the measurements. The dimensions of the coupler with transitions, which are shown in Figure 5a, are as follows: $1_{1}=5, l_{2}=15, l_{3}=25, R_{1}=1.21$, and $R_{2}=8.33$ (all in millimeter). The simulated results of the coupler with transitions are depicted in Figure $4 \mathrm{~b}$, from which we can see that the $S_{21}$ parameter and $S_{31}$ parameter were almost unchanged compared with the no transitions situation, which is shown in Figure $4 \mathrm{a}$, and the simulated $S_{11}$ parameter and $S_{41}$ parameter were below $-18.97 \mathrm{~dB}$ and $-19.16 \mathrm{~dB}$, respectively, in the full Ka band. Figure 5b shows the 3D-structure diagram of the prototype coupler. The exploded schematic of the coupler is depicted in Figure $5 \mathrm{c}$. 


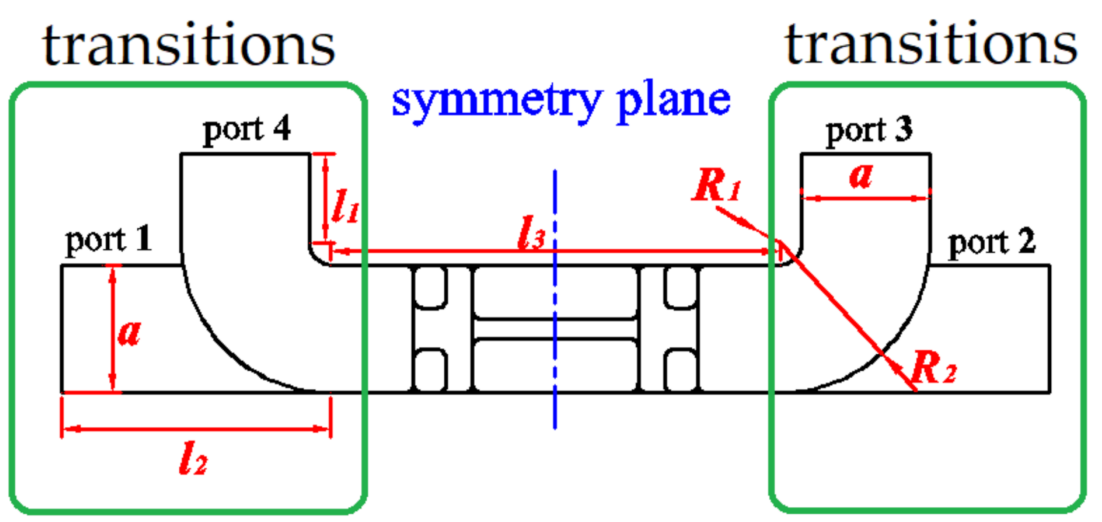

(a)

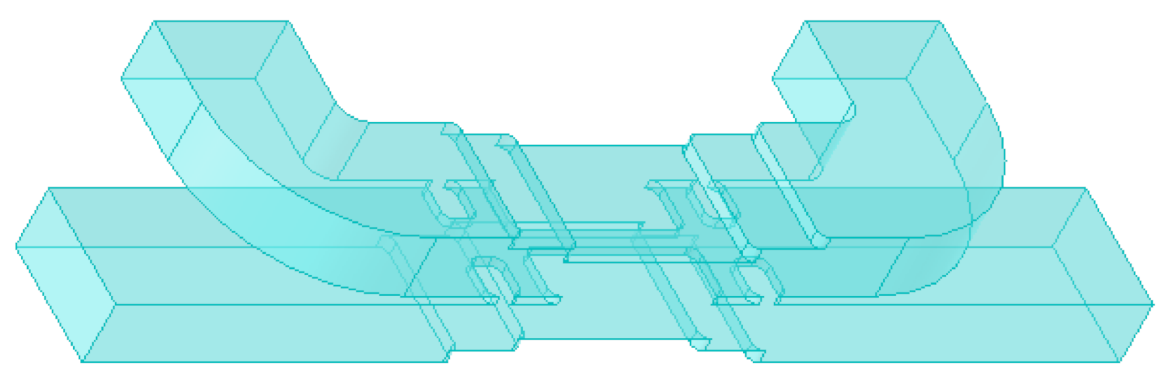

(b)

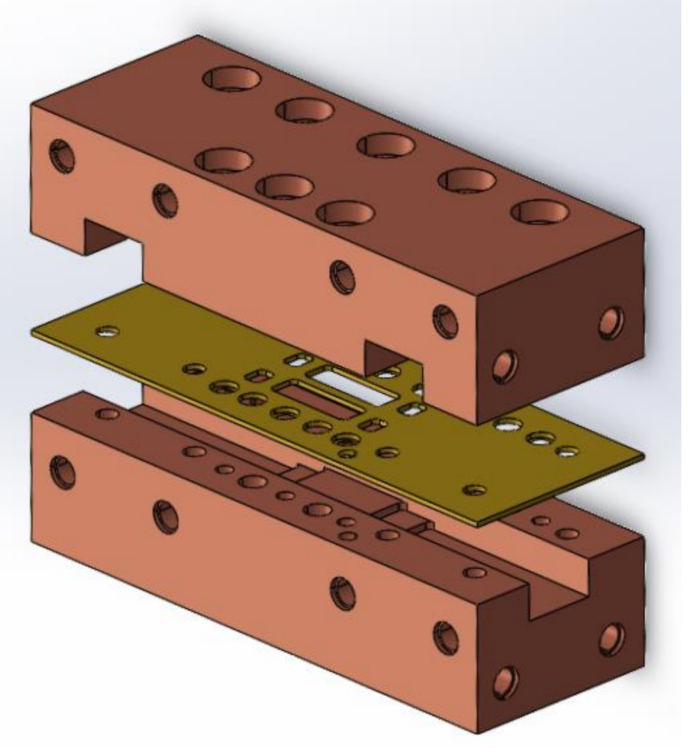

(c)

Figure 5. Prototype coupler (a) with transitions, (b) the 3D-structure diagram, and (c) exploded schematic.

\section{Results}

\subsection{Fabrication}

The $3 \mathrm{~dB}$ full Ka band waveguide directional coupler based on rectangular aperture arrays with stairs is fabricated according to the configuration parameters given above and assembled/disassembled pictures are shown in Figure 6. The coupler is fabricated by a brass nut, gold plate. 


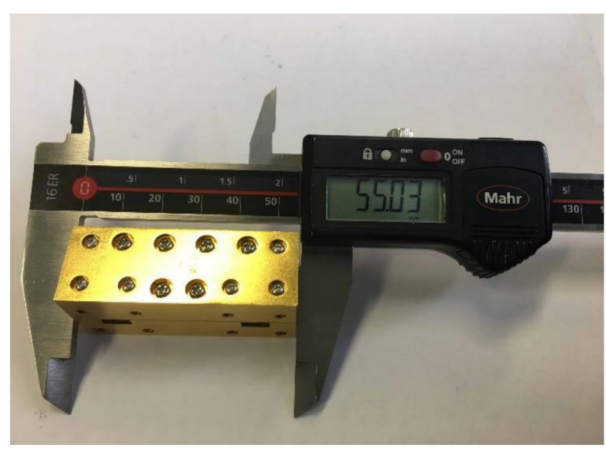

(a)

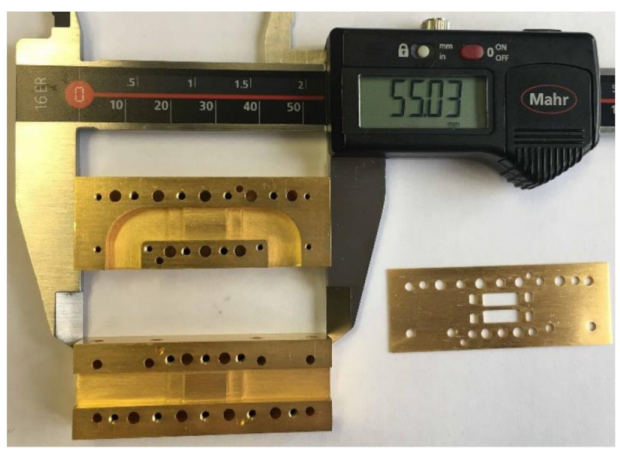

(b)

Figure 6. Photograph of sample coupler (a) assembled and (b) disassembled (the dimensions of sample coupler are $55.03 \times 20.02 \times 25.02 \mathrm{~mm}^{3}$ ).

\subsection{Measurement Results}

The measured results were performed using an Agilent N5224A (Keysight Technologies, Santa Rosa, California, U.S.) network analyzer. The calibration method used is the Short-Load-Open-Thru (SLOT) method. The measured results and simulated results are shown in Figure 7. Over the full waveguide bandwidth from $26.5 \mathrm{GHz}$ to $40 \mathrm{GHz}$, the measured $\mathrm{S}_{11}$ magnitude and $\mathrm{S}_{41}$ magnitude were below $-17.46 \mathrm{~dB}$ and $-20.82 \mathrm{~dB}$, respectively. The $S_{21}$ magnitude varied from -2.89 to $-4.26 \mathrm{~dB}$, while coupling strength $\left(\mathrm{S}_{31}\right.$-magnitude) changed from -2.74 to $-3.80 \mathrm{~dB}$. A power-split unbalance within $0.76 \mathrm{~dB}$ was achieved. The simulated and measured results of $S_{21}$ and $S_{31}$ are in good agreement. Some deviations between them may be caused by unexpected tolerances in fabrication, inaccurate material parameters, or loss of electromagnetic energy. The difference between simulation and measurement of $S_{11}$ may be caused by imperfect parameters of the transitions and loads used in the test, and the difference of $S_{41}$ may be caused by testing with no transitions and loads. The proposed coupler has a better performance in coupling flatness using smaller sizes compared with the couplers [5-8]. The conventional ones (coupling region) need several $\lambda \mathrm{g}$ ( $\lambda \mathrm{g}$ is operation wavelength of center frequency) to achieve the performance shown in Table 1, while the sample coupler (coupling region) only needs $1.35 \times \lambda \mathrm{g}(15.82 \mathrm{~mm})$ to realize tight coupling strength, full waveguide bandwidth, and better coupling flatness. The overall sizes of the coupler are $55.03 \times 20.02 \times 25.02 \mathrm{~mm}^{3}$.

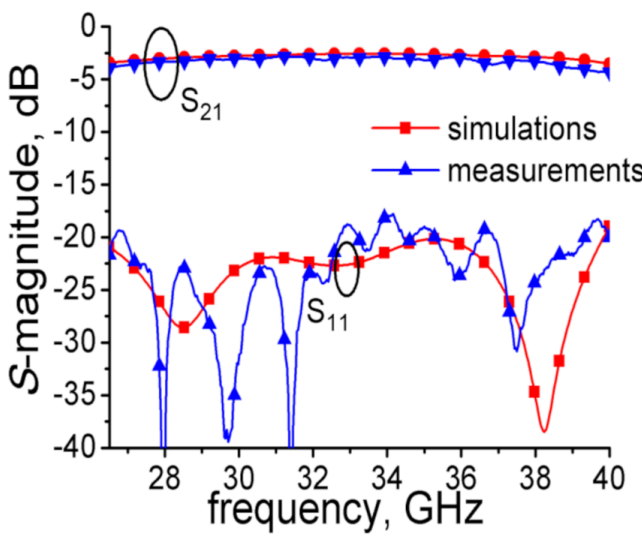

(a)

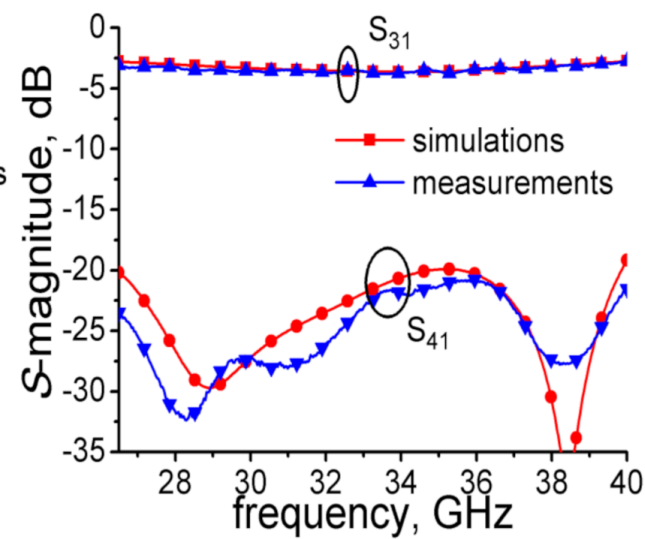

(b)

Figure 7. Simulated and measured results of the sample coupler: (a) $S_{11}$ and $S_{21}$ and (b) $S_{31}$ and $S_{41}$.

\subsection{Sensitivity Analysis}

Unexpected tolerances may occur during the fabrication process. The margin of machining error is within $\pm 0.01 \mathrm{~mm}$. To illustrate the effect of these machining errors, we simulated the $\mathrm{S}$ magnitude using key structure parameters $\left(\mathrm{b}_{1}, \mathrm{~b}_{2}, \mathrm{w}_{1}, \mathrm{~h}_{1}, \mathrm{w}_{3}\right.$, and $\left.\mathrm{h}_{2}\right)$ 
with errors, which are shown in Figure $8\left(\triangle \mathrm{x}=-0.01 \mathrm{~mm}: \mathrm{b}_{1}=0.7, \mathrm{~b}_{2}=1.46, \mathrm{w}_{1}=9.21\right.$, $\mathrm{h}_{1}=3.02, \mathrm{w}_{3}=1.81$, and $\mathrm{h}_{2}=2.39 ; \Delta \mathrm{x}=0 \mathrm{~mm}: \mathrm{b}_{1}=0.71, \mathrm{~b}_{2}=1.47, \mathrm{w}_{1}=9.22, \mathrm{~h}_{1}=3.03$, $\mathrm{w}_{3}=1.82$, and $\mathrm{h}_{2}=2.4 ; \triangle \mathrm{x}=0.01 \mathrm{~mm}: \mathrm{b}_{1}=0.72, \mathrm{~b}_{2}=1.48, \mathrm{w}_{1}=9.23, \mathrm{~h}_{1}=3.04, \mathrm{w}_{3}=1.83$, and $\mathrm{h}_{2}=2.41$ (all in millimeters)). As it can be observed, this design is very robust.

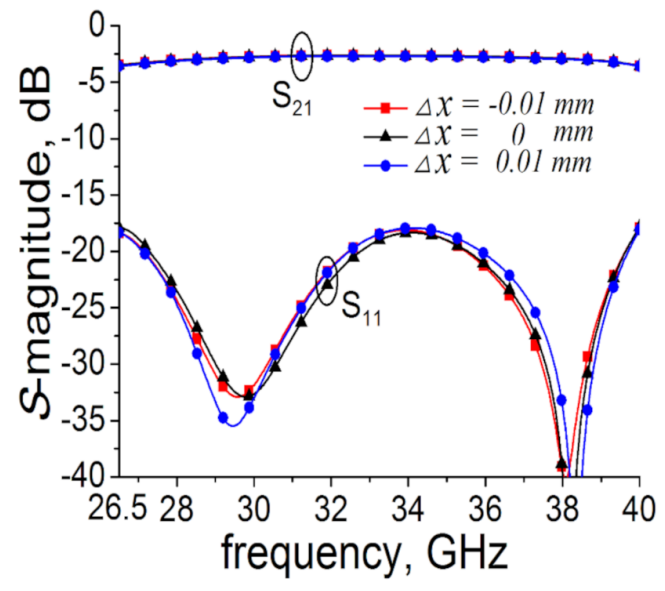

(a)

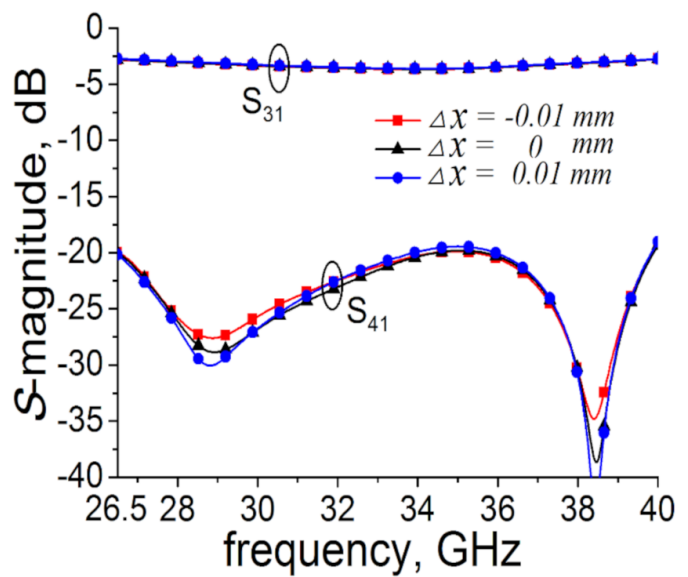

(b)

Figure 8. Sensitivity analysis: (a) $S_{11}$ and $S_{21}$ and (b) $S_{31}$ and $S_{41}$.

\section{Conclusions}

In this paper, a compact full Ka-band waveguide directional coupler is presented, which has good coupling flatness and broad bandwidth. Over the full Ka band from $26.5 \mathrm{GHz}$ to $40 \mathrm{GHz}$, the $\mathrm{S}_{11}$ magnitude and $\mathrm{S}_{41}$ magnitude were below $-17.46 \mathrm{~dB}$ and $-20.82 \mathrm{~dB}$, respectively. The $\mathrm{S}_{21}$ magnitude varied from -2.89 to $-4.26 \mathrm{~dB}$, while coupling strength ( $\mathrm{S}_{31}$-magnitude) changed from -2.74 to $-3.80 \mathrm{~dB}$. A power-split unbalance within $0.76 \mathrm{~dB}$ was achieved. The length of the coupling region is only $15.82 \mathrm{~mm}$. The overall sizes of the coupler are $55.03 \times 20.02 \times 25.02 \mathrm{~mm}^{3}$. The novel coupler can be easily designed to other frequency ranges and different coupling coefficients by following the design process given above. The proposed coupler could be a good candidate for miniaturized microwave system applications such as radar systems, communication systems, and microwave imaging systems. Based on this article, the research of deformable directional coupler, terahertz directional coupler may be carried out in the future.

\section{Patents}

The coupler proposed in this article has obtained Chinese patent protection, the patent number is ZL 202010225946.3.

Author Contributions: Conceptualization, methodology, analysis, and writing, X.D. (Xida Deng); measurement, X.D. (Xuan Dai); supervision, G.D.; funding acquisition, J.D. and G.D. All authors have read and agreed to the published version of the manuscript.

Funding: This work was funded by the Beijing Municipal Natural Science Foundation (No.4192016) and High efficiency and compact motion human microwave security inspection system for large-scale application (No.2017YFE0123200).

Institutional Review Board Statement: Not applicable.

Informed Consent Statement: Not applicable.

Data Availability Statement: Data is contained within the article.

Conflicts of Interest: The authors declare no conflict of interest. 


\section{References}

1. Bethe, H.A. Theory of diffraction by small holes. Phys. Rev. 1944, 66, 163. [CrossRef]

2. Kawai, T.; Kishihara, M.; Kokubo, Y.; Ohta, T. Cavity-type directional couplers with simple structure. In Proceedings of the 1997 IEEE MTT-S International Microwave Symposium Digest, Denver, CO, USA, 8-13 June 1997; pp. $413-416$.

3. Riblet, H.J. The short-slot hybrid junction. Proc. IRE 1952, 40, 180-184. [CrossRef]

4. Hildebrand, L.T. Results for a simple compact narrow-wall directional coupler. IEEE Microw. Guided Wave Lett. 2000, 10, $231-232$. [CrossRef]

5. Levy, R. Analysis and synthesis of waveguide multiaperture directional couplers. IEEE Trans. Microw. Theory Tech. 1968, 16, 995-1006. [CrossRef]

6. Yeo, S.; Lee, K. Improvements in design of six-port reflectometer comprising symmetrical five-port waveguide junction and directional coupler. IEEE Trans. Instrum. Meas. 1990, 39, 184-188. [CrossRef]

7. Niu, Z.; Zhang, B.; Ji, D.; Yang, Y.; Liu, Y.; Feng, Y.; Fan, Y.; Chen, Z.; Chen, X.; Li, D. A Novel 3-dB Waveguide Hybrid Coupler for Terahertz Operation. IEEE Microw. Wirel. Compon. Lett. 2019, 29, 273-275. [CrossRef]

8. Liu, S.; Xu, F. Compact multilayer half mode substrate integrated waveguide 3-dB coupler. IEEE Microw. Wirel. Compon. Lett. 2018, 28, 564-566. [CrossRef]

9. Wang, K.; Shea, D.; Zhang, X.; Yuan, H. Wideband 3-dB Coupler Based on Substrate Integrated Gap Waveguide. In Proceedings of the 2018 International Conference on Microwave and Millimeter Wave Technology (ICMMT), Chengdu, China, 7-11 May 2018; pp. 1-3.

10. Longhi, M.; Galdeano, J.; Morini, A.; Baldelli, M.; Angeletti, P.; Toso, G.; Venanzoni, G. Dual-polarization beam forming networks based on high order directional couplers. In Proceedings of the 2017 11th European Conference on Antennas and Propagation (EUCAP), Paris, France, 19-24 March 2017; pp. 2820-2823.

11. Doghri, A.; Djerafi, T.; Ghiotto, A.; Wu, K. Substrate integrated waveguide directional couplers for compact three-dimensional integrated circuits. IEEE Trans. Microw. Theory Tech. 2014, 63, 209-221. [CrossRef]

12. Ali, M.M.M.; Shams, S.I.; Sebak, A. Ultra-wideband printed ridge gap waveguide hybrid directional coupler for millimetre wave applications. IET Microw. Antennas Propag. 2019, 13, 1181-1187.

13. Miralles, E.; Belenguer, A.; Esteban, H.; Boria, V. Cross guide Moreno directional coupler in empty substrate integrated waveguide. Radio Sci. 2017, 52, 597-603. [CrossRef]

14. Tavakoli, M.J.; Mallahzadeh, A.R. Wideband directional coupler for millimeter wave application based on substrate integrated waveguide. Emerg. Sci. J. 2018, 2, 93-99. [CrossRef]

15. Veadesh, B.; Aswin, S.; Shambavi, K. Design and analysis of C-band SIW directional coupler. In Proceedings of the 2017 International conference on Microelectronic Devices, Circuits and Systems (ICMDCS), Vellore, India, 10-12 August 2017; pp. 1-5.

16. Parment, F.; Ghiotto, A.; Vuong, T.-P.; Duchamp, J.-M.; Wu, K. Air-to-dielectric-filled two-hole substrate-integrated waveguide directional coupler. IEEE Microw. Wirel. Compon. Lett. 2017, 27, 621-623. [CrossRef]

17. Chandrasekaran, K.; Alphones, A.; Karim, M. Graded index substrate integrated waveguide based directional coupler. In Proceedings of the 2017 IEEE International Symposium on Antennas and Propagation \& USNC/URSI National Radio Science Meeting, San Diego, CA, USA, 9-14 July 2017; pp. 2255-2256.

18. Zhang, Y.; Wang, Q.; Xin, H. A Compact 3 dB E-Plane Waveguide Directional Coupler With Full Bandwidth. IEEE Microw. Wirel. Compon. Lett. 2014, 24, 227-229. [CrossRef]

19. Cheng, Y.J.; Hong, W.; Wu, K.; Fan, Y. A hybrid guided-wave structure of half mode substrate integrated waveguide and conductor-backed slotline and its application in directional couplers. IEEE Microw. Wirel. Compon. Lett. 2011, 21, 65-67. [CrossRef]

20. Fernandez, M.D.; Ballesteros, J.A.; Belenguer, A. Design of a hybrid directional coupler in empty substrate integrated waveguide (ESIW). IEEE Microw. Wirel. Compon. Lett. 2015, 25, 796-798. [CrossRef]

21. Li, T.; Dou, W. Substrate integrated waveguide 3 dB directional coupler based on air-filled vias. Electron. Lett. 2017, 53, 611-613. [CrossRef] 